${ }^{4}$ INSERM, U1168, VIMA: Aging and chronic diseases. Epidemiological and public health approaches \& University Versailles Saint-Quentin-en-Yvelines, Villejuif, France

${ }^{5}$ Division of Environmental Health Sciences, School of Public Health, University of California, Berkeley, Berkeley, California, USA

\section{0a A RIGHTS-BASED APPROACH TO ACCESS TO OCCUPATIONAL HEALTH SERVICES - WHAT MIGHT THAT OFFER WORKING POPULATIONS IN THE DEVELOPING WORLD?}

Leslie London*. School of Public Health and Family Medicine, University of Cape Town, South Africa

\subsection{6/oemed-2018-ICOHabstracts.366}

The majority of workers worldwide remain without adequate access to Occupational Health Services (OHS), particularly with regard to gaps in implementation, coverage, content, and capacity building. Yet access to OHS is an essential element of the right to health and is recognised in numerous global human rights agreements as being a fundamental human right. Even in situations of resource scarcity, states have obligations to formulate, implement, monitor and evaluate occupational health laws and policies, and to facilitate the participation of workers in these activities. Rather than counting OHS as a cost to production, it is important to frame OHS as a valuedriven enterprise which can benefit all stakeholders, both employers and employees and provide a fair and accepted framework for managing conflicting interests. More importantly, OHS as a rights-based activity will reach beyond the traditional formal sector and challenge governments to address the $\mathrm{OH}$ needs of informal sector workers and other working populations currently lying outside of traditional regulatory perspectives - a particularly important requirement for Low and Middle-Income countries. Not all countries will enjoy the same resources to implement OHS's and rationing decisions may result in different levels of OHS provision. However, a Rights-based approach to OHS provision will identify basic OHS standards consistent with core obligations on states, will impose constitutional limits on the extent to which rationing decisions adversely impact on OHS provision, will force stakeholders to pursue equity-related policies and will open participatory spaces for citizens and communities to assert rights to workplace health and safety, across formal and informal sectors. This approach provides a huge opportunity for leverage for OHS in the developing world which $\mathrm{OH}$ practitioners should support through their research, service and advocacy.

\section{$1720 \mathrm{~b}$ IMPACTS OF OCCUPATIONAL HEALTH SERVICE NETWORK TO REPORTING OCCUPATIONAL DISEASES}

${ }^{1}$ Leon Guo*, ${ }^{2}$ Po-Chin Chu. ${ }^{1}$ National Institute of Environmental Health Sciences, National Health Research Institutes, Taiwan; ${ }^{2}$ Environmental and Occupational Medicine, National Taiwan University College of Medicine and NTU Hospital, Taipei, Taiwan

10.1136/oemed-2018-ICOHabstracts.367
Occupational disease are frequently underreported, therefore their importance in health consequences. This hinders the progress in occupational health and safety. To address this problem, several medical centres and the labour authority of Taiwan founded the Network of Occupational Diseases and Injuries Service (NODIS) for occupational disease and injury services and established a new Internet-based reporting system. The impacts of the Centres for Occupational Disease and Injury Services and their local network hospitals on compensable occupational diseases were analysed, and the distribution of occupational diseases across occupations and industries were described from 2005 to 2016. The NODIS reporting dataset and the National Labour Insurance scheme's dataset of compensated cases were used. The annual incidence of reported occupational diseases from the NODIS was compared with the annual incidence of compensable occupational diseases from the compensated dataset during the same period. It is found that after the establishment of the NODIS, the two annual incidence rates of reported and compensable occupational disease cases have increased by several folds from 2007 to 2016. The reason for this increased reporting and compensable cases may be the implementation of the new government-funded Internet-based system and increasing availability of hospitals and clinics to provide occupational health services. During the 2008-2016 period, the most frequently reported occupational diseases were carpal tunnel syndrome, lumbar disc disorder, upper limb musculoskeletal disorders, and contact dermatitis. It is concluded that the network and reporting system was successful in providing more occupational health services to workers, assisting the diagnosis of compensable occupational diseases, and reducing underreporting of occupational diseases. The experience in Taiwan could serve as an example for other newly developed countries facing underdiagnosis and under-reporting of occupational diseases.

\section{C OPPORTUNITIES TO INSERT OCCUPATIONAL HEALTH COMPONENTS INTO NATIONAL HEALTH POLICIES AND PROGRAMS: VIEWS AND EXPERIENCES}

R Mendes. National Association of Occupational Medicine (ANAMT), São Paulo - SP, Brazil

\subsection{6/oemed-2018-ICOHabstracts.368}

Several countries, like Brazil, where Workers' Health is a clear responsibility and mandate of the Ministry of Health, are supposed to develop health policies that include basic components of the 'Occupational Health thinking' and approaches. These components should be included into all levels of health services, depending on the mission, responsibility and complexity of each level, as well as on the geographical coverage and mandate. Such countries, fortunately, have structured their national system taking the Primary Health Care approach as the main 'organiser' of the whole health system. Primary Heath Care has received some variations, and the Brazilian case is based on the Family Heath Care approach, that may be an appropriate advancement. So, entering through the 'door' of the Health System - i.e. the Family Health Care approach or program - it is possible to reach and access the full System, from the primary level to more elevated and complex levels. The main components of the 'Occupational 